\title{
CALIDAD DE VIDA FAMILIAR Y ATENCIÓN TEMPRANA: VALORACIONES Y EXPECTATIVAS SOBRE EL ROL DE LA FISIOTERAPIA
}

\author{
Clarissa Altina Cunha de Araujo \\ Directores: Dra. Berta Paz Lourido, Dr. Sebastià Verger Gelabert \\ Programa de Doctorado en Investigación \\ e Innovación en Educación \\ Universitat de les Illes Balears - España
}

T radicionalmente, los estudios sobre la calidad de vida, que incluían las familias, se limitaban a los efectos de tener un familiar con discapacidad o con enfermedades crónicas en la calidad de vida individual. Investigaciones recientes se han centrado en la calidad de vida de la familia en su conjunto. A su vez, el Libro Blanco de la Atención Temprana también dirige la mirada hacia las familias cuando recoge que las intervenciones en ese ámbito se dirigen a la población infantil de 0-6 años, a la familia y al entorno. Por otro lado, la fisioterapia pediátrica se ha desarrollado cada vez más en los últimos años en ese contexto. Sin embargo, la mayoría de los estudios revelan que la participación de los padres frecuentemente es considerada como un recurso terapéutico, que puede tener un efecto negativo en la calidad de vida familiar. Este estudio tiene como objetivo analizar las percepciones sobre la fisioterapia en la intervención temprana en Mallorca y su influencia en la calidad de vida familiar desde la perspectiva de los fisioterapeutas; así como de los padres y de las madres de niños con discapacidad. Se trata de una investigación cualitativa fundamentada en una perspectiva crítico social. La muestra intencional se compone de fisioterapeutas que trabajan en servicios públicos, concertados y privados de atención temprana en Mallorca con diferentes tiempos de experiencia. Han participado también padres y madres de niños con distintas afectaciones. Entre ellos se incluyen las familias de niños que fueron tratados en uno o más servicios de atención temprana. La selección de los participantes se llevó a cabo con el apoyo de informantes clave en secuencia encadenada. En total, 29 informantes (9 fisioterapeutas, 4 padres y 16 madres) aceptaron participar voluntariamente en el estudio y firmaron un consentimiento informado antes de la entrevista. La información se recogió en 21 entrevistas semiestructuradas en profundidad (9 fisioterapeutas y 12 madres) y 4 díadas (madre y padre) hasta que se alcanzó la saturación de la información. Las sesiones fueron grabadas, luego transcritas y analizadas mediante el análisis del discurso. Como estrategia de rigor metodológico, se ha realizado la triangulación de la información a través de diferentes fuentes y métodos. Los resultados de este estudio muestran que los colectivos entrevistados consideran que la calidad de vida familiar se compone de elementos que caracterizan la vida en familia, la adaptación al nuevo contexto en consecuencia de la condición del niño, los apoyos, la calidad de vida del niño, y, por último, los recursos económicos. Con relación a la influencia de la fisioterapia en la calidad de vida familiar, los participantes relataron tanto aspectos que son favorables como otros que pueden generar efectos no deseados. Estos elementos fueron agrupados en categorías en relación a la atención al niño, a la atención a las familias, a la fisioterapia en los centros sanitarios de atención temprana y, finalmente, a la fisioterapia en otros entornos. Como conclusiones, se observa que la intervención de fisioterapia en atención temprana se centra fundamentalmente en el niño y su discapacidad, otorgando a la familia una condición de soporte continuado en relación a la terapia. Ello, sin embargo, puede poner en riesgo aspectos de la calidad de vida familiar que también tienen un impacto en el niño teniendo en cuenta los determinantes sociales de la salud. Además, este estudio ha permitido poner de relieve otros elementos que en conjunto generan un contexto de inequidades socio-sanitarias y económicas con impacto en las familias. Se sugiere implicaciones a distintos niveles orientados en mejorar la atención temprana y la fisioterapia en particular, reorientando los servicios hacia el enfoque de la calidad de vida familiar.

Palabras clave: calidad de vida familiar; atención temprana; fisioterapia pediátrica; investigación cualitativa; perspectiva crítico social. 